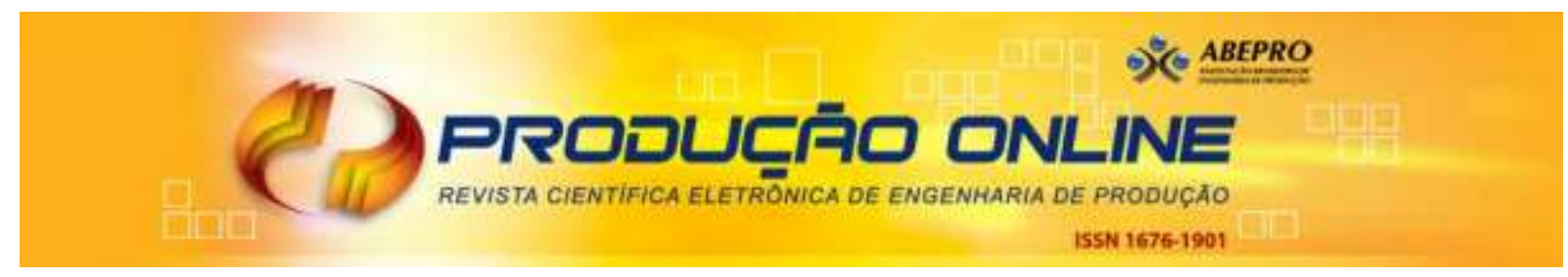

\title{
OS ESTUDANTES DE ENGENHARIA E AS SUAS INTENÇÕES EMPREENDEDORAS
}

\section{ENGINEERING STUDENTS AND THEIR ENTREPRENEURIAL INTENTIONS}

\author{
Filipa Dionísio Vieira* E-mail: filipadv@dps.uminho.pt \\ Cristina Santos RodriguesE-mail:crodrigues@dps.uminho.pt \\ *Universidade do Minho, Portugal
}

Resumo: No ambiente atual a promoção do empreendedorismo é uma oportunidade chave, e o ensino da engenharia tem reconhecido a sua relevância ao incluir nos seus currículos disciplinas básicas relacionadas com as áreas financeiras. Na situação econômica atual, fornecer ao futuro engenheiro conceitos e técnicas, que lhe permita passar do conhecimento para a ação, é indispensável para melhorar a compreensão do valor do empreendedorismo como uma alternativa de empregabilidade em detrimento de outras opções. O objetivo deste trabalho é o de apresentar os resultados preliminares da pesquisa ENGEmpreende desenvolvida para analisar as atitudes percebidas e os valores associados ao empreendedorismo por parte dos estudantes de engenharia. A amostra envolveu 387 estudantes dos cursos de engenharia da Universidade do Minho, em Portugal. Os estudantes de engenharia portugueses revelaram que têm uma boa opinião sobre o empreendedorismo. Este estudo também mostrou que a predisposição empreendedora dos estudantes inquiridos tem relações de dependência com o gênero, o conceito sobre empreendedorismo e o comportamento empreendedor. Os resultados sobre a imagem percebida do empresário sugerem que os estudantes reconhecem que o empreendedor tem uma imagem positiva na sociedade, mas têm dúvidas sobre o que é melhor: ser empresário ou ser um empregado numa grande empresa. Como barreiras, os estudantes de engenharia apresentam uma dificuldade em encontrar uma ideia de negócio ou como obter acesso a capitais de investimento através de empréstimos bancários. As capacidades e competências percebidas dos estudantes sugerem uma elevada adaptabilidade, confiança, confiança técnica e orientação para os resultados. Pretende-se com os resultados obtidos, por meio do questionário ENGEmpreende, contribuir para o tema de intenções empreendedoras de estudantes de engenharia, a fim de identificar as atitudes empreendedoras, predisposição para o autoemprego, imagem empresarial, obstáculos que interferem ao espírito empresarial, conhecimento sobre os riscos e confiança técnica.

Palavras-chave: Intenção Empreendedora. Comportamento Empreendedor. Estudantes de Engenharia.

Abstract: Promoting entrepreneurship is a key opportunity in the current environment, and engineering have recognized this criticism by including in their curricula basic financial disciplines. Given the current economic situation, provide the future engineer with concepts and techniques to move from knowledge to action, can improve the value perception of entrepreneurship as an alternative to employability on behalf of others. The aim of this paper is to present the preliminary results of the ENGEmpreende survey developed to measure the perceived attitudes and values of entrepreneurship by engineering students. Our sample involves 387 students of engineering courses from University of Minho. Portuguese engineering students report good levels of thoughts about entrepreneurship. Our study also found that their entrepreneurship predisposition has dependency relationships with gender, thoughts about entrepreneurship and entrepreneurial activities. The results of the perceived image of the entrepreneur suggest that students recognize the positive image of the entrepreneur in society, but have doubts about what is best: entrepreneur or employee in a large

Revista Produção Online, Florianópolis, SC, v.14, n. 1, p. 242-263, jan./mar. 2014. 
company? As perceived barriers, engineering students perceive as difficult to find a business idea or access to bank loans. Students' perceived skills and competence suggest a perceived high adaptability, perseverance, technical confidence and orientation to results. The results of ENGEmpreende survey give an additional contribution to the theme of engineering entrepreneurship intentions through the identification of entrepreneurship predisposition, attitude to self-employment, entrepreneurial image, barriers to entrepreneurship, risk perception and technical confidence.

Keywords: Entrepreneurial Intentions. Entrepreneurial Behavior. Engineering Students.

\section{INTRODUÇÃO}

Empreendedorismo consiste na criação de um novo negócio, como por exemplo emprego próprio ou no desenvolvimento de novas oportunidades em organizações/empresas já existentes. Por contribuir para a criação de uma cultura empresarial dinâmica, onde as empresas procuram progredir na cadeia de valor, num ambiente econômico global, o empreendedorismo encontra-se no centro da política econômica e industrial (GEM, 2010). É hoje em dia, geralmente reconhecido como um motor do desenvolvimento econômico (HARBI e ANDERSON, 2010). De acordo com Heertje (1982) a resolução de alguns dos problemas da atualidade, que se verificam quer no setor privado, quer no setor público, passa pela atividade empresarial em larga escala, baseada numa atitude sensível e inovadora. Os empreendedores são responsáveis pelo desenvolvimento econômico, pela introdução e implementação de ideias inovadoras, que originam inovações de produto, inovações de processo, inovações de marketing e inovações organizacionais. A implementação destas novas ideias, pelos empreendedores, permite a criação de novas empresas, que oferecem novos produtos ou serviços, para satisfazer as necessidades de novos clientes. Essas novas empresas permitirão o crescimento econômico e a criação de novos empregos para a população ativa (VAN PRAAG, 1999). Wong et al. (2005) afirmam que as pequenas empresas e as empresas recém-formadas permitem a criação de um número significativo de novos empregos, acrescentando ainda, que alguns estudos mostram que as pequenas e novas empresas têm criado a maioria dos novos empregos.

Muitos investigadores têm-se interessado pela temática do empreendedorismo, nomeadamente a identificação e estudo dos fatores que explicam o comportamento empreendedor dos indivíduos. Na área da psicologia, tem sido demonstrado o poder explicativo da intenção como um importante indicador

Revista Produção Online, Florianópolis, SC, v.14, n. 1, p. 242-263, jan./mar. 2014. 
do comportamento empreendedor. Compreender a formação de intenção de empreender é importante para a compreensão do comportamento empreendedor. A intenção empreendedora pode ser vista como um indicador preciso do comportamento planeado para a criação de um novo negócio.

A propagação dos efeitos negativos da crise econômico-financeira internacional tem afetado significativamente a atividade econômica portuguesa, com particular destaque e impacto na taxa de desemprego do país e nas condições de funcionamento da sua economia. A recuperação e o desenvolvimento da economia nacional passam fundamentalmente pelo aparecimento de empreendedores, capazes de identificar e aproveitar oportunidades, investir e gerar riqueza e emprego (GEM, 2010).

Perante a atual situação econômica de Portugal, onde 0 tradicional empreendedor não tem habilitações ao nível do ensino superior e a taxa de desemprego nos indivíduos com grau superior de ensino cresceu $170 \%$ em 10 anos (INE, 2012), fornecer aos futuros engenheiros conceitos e técnicas para passar do conhecimento para a ação, pode melhorar a percepção do real valor do empreendedorismo como uma alternativa de empregabilidade. Um estudo recente confirma uma nova geração de empreendedores portugueses com qualificações mais elevadas (LINI, 2009). Neste contexto, é oportuno analisar as intenções empreendedoras de estudantes universitários portugueses, nomeadamente ao nível dos cursos de engenharia, sem experiência prévia em disciplinas de empreendedorismo.

O artigo está estruturado da seguinte forma. A Seção 2 apresenta alguns conceitos sobre comportamento empreendedor e faz uma breve análise sobre as tendências e importância do ensino do empreendedorismo. Na Seção 3 são apresentados os resultados do inquérito aplicado aos estudantes de engenharia, com o objetivo de explorar as suas atitudes e percepções empreendedoras. Por último, na seção 4, são apresentadas as principais conclusões.

\section{INTENÇÃO EMPREENDEDORA}

Considerando que o empreendedorismo contribui para a criação de uma cultura empresarial dinâmica, pois permite que as empresas evoluam e se tornem 
mais competitivas, a recuperação e o desenvolvimento da economia dependem fortemente do aparecimento de empreendedores, que tenham capacidade de identificar e aproveitar oportunidades, investir e gerar riqueza e emprego. O empreendedorismo é um fator crítico na promoção da inovação, na criação de emprego e no desenvolvimento econômico de um país.

Em muitos países o empreendedorismo encontra-se no centro da política econômica e industrial, em que o principal objetivo é a sua promoção (ver por exemplo Jabbour e Fonseca (2005), Miziara e Carvalho (2008) e Andrade Júnior (2012)). Na verdade, Drucker (2006) refere que o empreendedorismo não é nem uma ciência nem uma arte, mas pode ser aprendido e deve ser praticado, porque os empreendedores não nascem, mas são moldados. Por isso torna-se relevante a promoção do empreendedorismo por entidades públicas e privadas, com o objetivo de incentivar a sua prática ao transmitir competências e ao desmistificar o conceito, para que não haja medo do possível insucesso.

O empreendedorismo possui características variadas e peculiares e pode se manifestar de diversas formas, o que torna difícil a sua definição. Ainda assim, é possível concluir que a sua origem está no reconhecimento de uma oportunidade ou necessidade sentida pelo mercado. Segundo D' Este et al. (2012) a literatura sobre empreendedorismo define o ato de empreendedorismo como estando orientado para a descoberta, avaliação e exploração de oportunidades lucrativas. Hisrich et al. (2009) acrescentam ainda, que o empreendedorismo é o processo de criar algo novo com valor, dedicando o tempo e os esforços necessários, assumindo os riscos financeiros, psíquicos e sociais correspondentes, e recebendo as consequências da satisfação e da independência.

Para a identificação e estudo dos fatores que explicam o comportamento empreendedor, as características do indivíduo, e a existência de oportunidades de mercado e a tecnologia, são referidas como as mais importantes. Estudos realizados mostram que o perfil do empreendedor depende principalmente de fatores motivacionais, sendo os mais importantes: a realização pessoal, o potencial de novas tecnologias, as oportunidades de negócios, o desejo de independência e necessidades mais intensas para alcançar os seus objetivos (ver por exemplo Miziara e Carvalho, 2008). 
No entanto, existem outros fatores psicológicos que devem também ser tidos em consideração, alguns com maior impacto do que outros, nomeadamente a necessidade de realização, a criatividade, a auto-eficácia, a propensão a inovar, a capacidade de partilhar, a liderança, a capacidade de comunicar, a confiança, a assunção de risco, a capacidade de tomar decisões, a humildade e a capacidade de fazer sacrifícios (DRUCKER, 2006).

Sing e DeNoble (2003) e Laspita et al. (2012) argumentam que indivíduos que fazem parte de famílias empreendedoras, isto é, possuem um negócio familiar, apresentam maiores intenções empreendedoras, aumentando as suas percepções de que o autoemprego é uma opção de carreira e que é possível obter rendimentos mais elevados. As intenções empreendedoras podem ser influenciadas por fatores genéticos. Além disso, as pessoas podem ter tendências genéticas que as tornam mais sensíveis as motivações ambientais, que podem representar oportunidades empreendedoras.

O background familiar, isto é, a existência de negócios na família, tem um efeito demonstrado no aumento da probabilidade de criação de um negócio próprio (BENETT e DANN, 2000; WANG e WONG; 2004). Contudo, na prática, muitos empreendedores não detêm este background familiar. Outra abordagem, baseada na identificação de perfil e capacidade empreendedora, tem evidenciado as dificuldades de identificação de um empreendedor em potencial e da previsão do comportamento futuro como empreendedor. Independentemente do background familiar e da personalidade dos indivíduos, o sistema educacional pode promover o designado "espírito empreendedor" antes da intenção de criação de um negócio próprio (FRUGIE et al., 2003).

Os decisores políticos acreditam que níveis mais elevados de empreendedorismo podem ser alcançados através da educação e, especialmente, através da educação para o empreendedorismo. Curteis (1997), Martins et al. (2002), Dolabela (2008) e Sarkar (2010) afirmam que o crescimento da capacidade empreendedora de um país depende da educação e do conhecimento cultural do empreendedorismo por parte de todos os cidadãos e que o empreendedorismo se desenvolve como um fenômeno cultural ligado ao desenvolvimento da educação. Vários autores, como Raijman (2001) e Askun e Yildirim (2011) defendem que a 
educação fornece as competências gerais, a formação e o conhecimento, que facilita o acesso ao mundo dos negócios. Uma vez, que permite aos indivíduos avaliar a extensão do mercado de trabalho, o tipo de bens ou serviços que são procurados pelos clientes e ainda, organizar o negócio. Para Carayannis et al. (2003) não há dúvida de que a educação para o empreendedorismo procura construir conhecimentos e competências, e também aumentar a probabilidade de sucesso empresarial.

Além disso, Lee e Wong (2003), Souitaris et al. (2007) e von Graevenitz et al. (2010) acrescentam que o ensino do empreendedorismo aumenta a intenção de iniciar um novo negócio. Por isso, a educação deve ser promovida e implementada nos currículos acadêmicos, o que está já ocorrendo em muitos países membros da União Europeia e nos Estados Unidos da América. Um pressuposto fundamental subjacente a esses programas é que as competências empreendedoras podem ser ensinadas e não são apenas características pessoais. De fato, tem sido demonstrado que; (1) a educação normal, isto é não especializada, medida em anos de escolaridade, tem um efeito positivo no desempenho empreendedor e, (2) a formação empresarial é efetiva para o desempenho de pessoas que se candidataram a programas de micro-crédito para iniciar seu próprio negócio (OOSTERBEEK et al., 2010).

Atualmente a promoção do empreendedorismo é uma oportunidade chave e o ensino da engenharia tem reconhecido essa pertinência ao incluir nos seus currículos acadêmicos disciplinas básicas da área financeira, como por exemplo, análise de custos, avaliação econômica de projetos e engenharia econômica. A componente técnica de engenharia tem sido complementada por componentes nãotécnicas, tais como: formação na criação de negócios.

\section{RECOLHA DE DADOS E RESPETIVA ANÁLISE}

Este artigo apresenta os resultados preliminares de um questionário desenvolvido, especificamente, para compreender as intenções empreendedoras de estudantes de engenharia, sem experiência prévia em disciplinas ou programas de formação em empreendedorismo. Assumindo uma amostra de conveniência, o questionário designado por ENGEmpreende foi aplicado a estudantes de cursos de

Revista Produção Online, Florianópolis, SC, v.14, n. 1, p. 242-263, jan./mar. 2014. 
engenharia da Universidade do Minho, que foram abordados nas aulas e convidados pessoalmente a participar no estudo. A amostra tem um total de 387 respondentes, divididos em estudantes de licenciatura $(78,55 \%)$ e estudantes de mestrado em engenharia $(21,45 \%)$. A distribuição por gênero reflete o domínio masculino entre os estudantes de engenharia $(60,47 \%$ são do gênero masculino e $39,53 \%$ são do gênero feminino). A idade média dos respondentes é de 22,26 anos com um desvio padrão de 5,036 anos e uma amplitude de valores entre os 17 e os 50 anos.

O estudo começa por questionar os respondentes sobre o comportamento empreendedor dos seus pais (LASPITA et al., 2012), mais concretamente "Cresceu numa família empreendedora i.e., tem pai e/ou mãe com negócio próprio?”. A Figura 1 apresenta a distribuição das respostas obtidas: $54,01 \%$ dos inquiridos admitem que os pais nunca foram empreendedores, contra os $45,73 \%$ que afirmaram que os pais têm ou tiveram um negócio próprio $(31,78 \%$ dos entrevistados indicaram que o negócio ainda está ativo, 9,30\% que o negócio acabou e funcionou há mais de 5 anos e 4,65\% que o negócio acabou, mas ainda funcionou pelo menos até há 5 anos).

Figura 1 - Comportamento empreendedor dos pais

Cresceu numa família empreendedora?

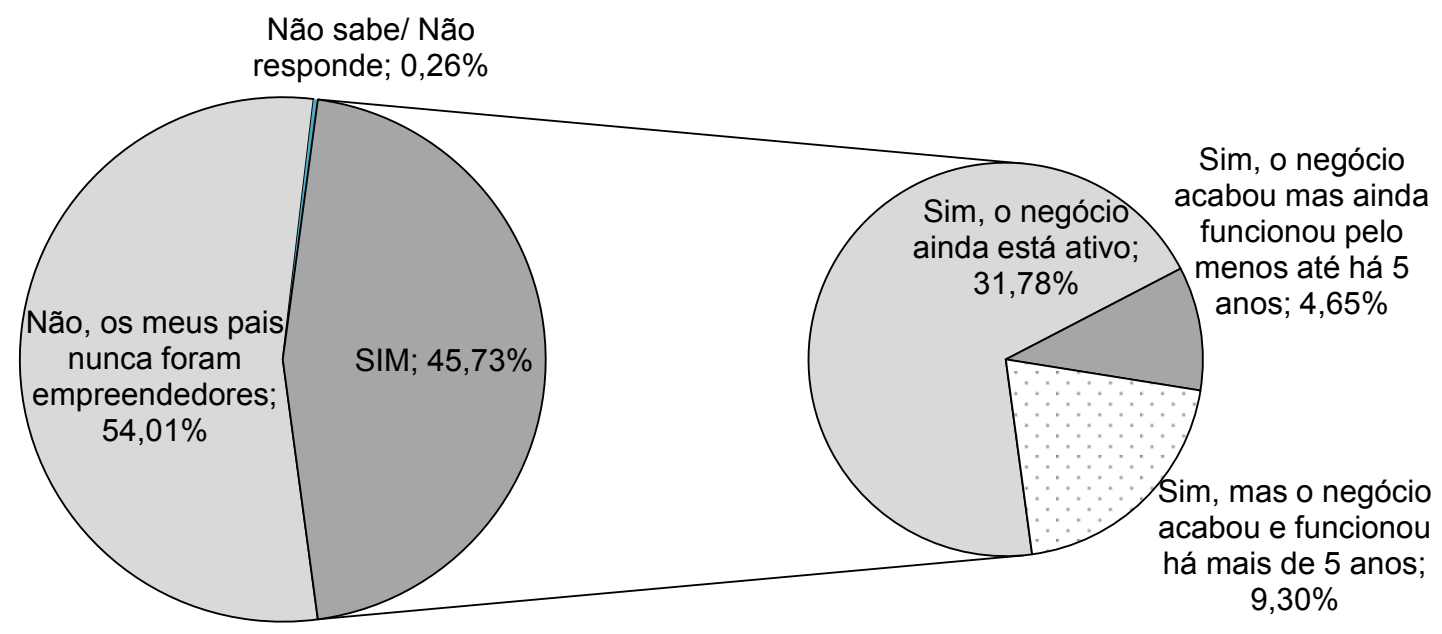

Fonte: Dados da pesquisa (2012) 
Com base nas respostas obtidas, foi criada uma nova variável para medir os pais em auto emprego pela codificação das respostas "sim" como 1-sim; caso contrário, 0-não.

Para analisar a intenção empreendedora, adaptou-se a questão da investigação de Laspita et al. (2012), tendo-se perguntado aos alunos se "Alguma vez ponderou seriamente iniciar o seu próprio negócio?". Das seis opções disponibilizadas, foi registrado que $33,25 \%$ dos respondentes assinalaram nunca ter pensado no assunto. No entanto, as respostas obtidas são essencialmente positivas (com um total de $65,98 \%$ ) com $45,27 \%$ afirmarem-se determinados a ser o seu próprio patrão no futuro. Ainda assim, 15,86\% admitem que abandonaram a ideia (ver Figura 2).

Figura 2 - Intenção empreendedora

Alguma vez ponderou seriamente iniciar o seu próprio negócio?

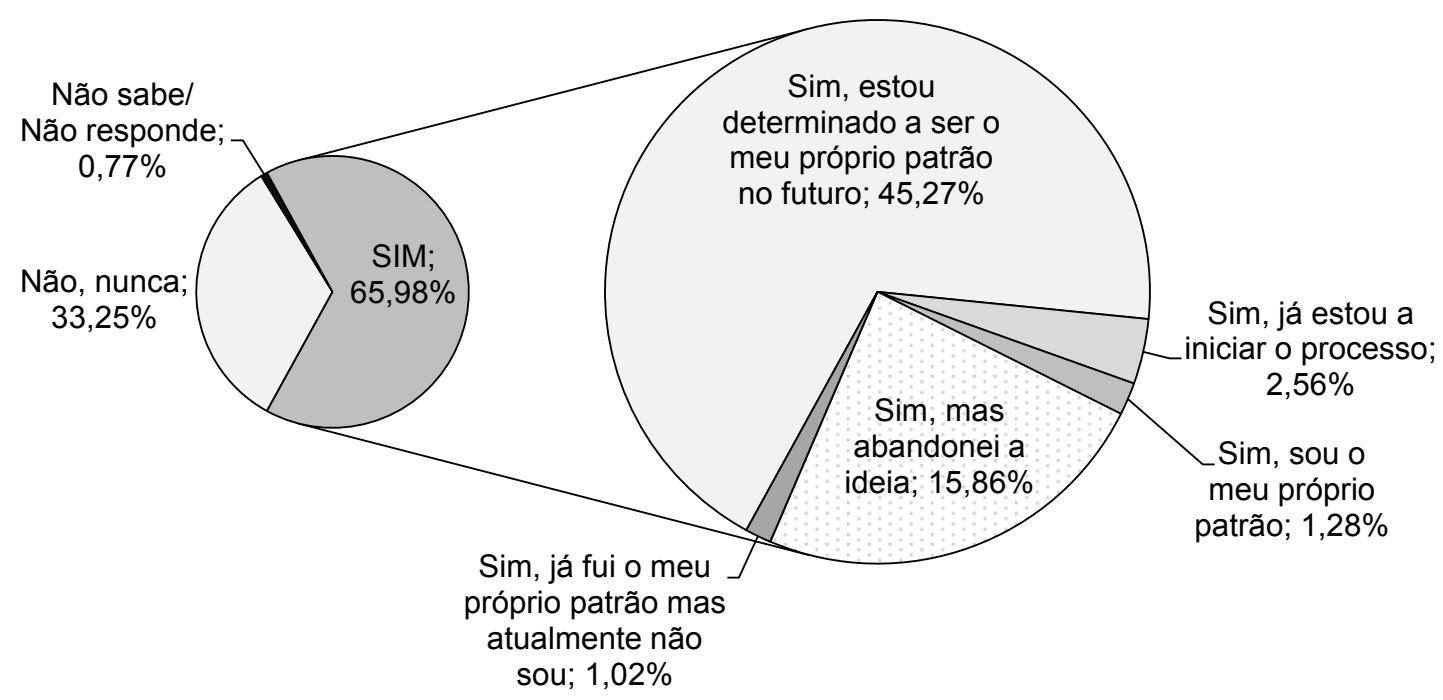

Fonte: Dados da pesquisa (2012)

Seguindo o procedimento de Laspita et al. (2012), que se refere a questão de intenção, foram deduzidas duas novas medidas: (1) opinião sobre empreendedorismo, que codifica as respostas positivas como 1-sim; caso contrário, 0-não, e (2) o comportamento empreendedor, que codifica as opções de resposta "Sim, eu já estou iniciar o processo", "Sim, sou o meu próprio patrão" e "Sim, já fui o meu próprio patrão, mas atualmente não sou" como 1-sim; caso contrário, 0-não.

Revista Produção Online, Florianópolis, SC, v.14, n. 1, p. 242-263, jan./mar. 2014. 
Segue-se uma análise exploratória das respostas dos estudantes sobre várias afirmações que refletem a predisposição empreendedora, a atitude para com o autoemprego, a imagem do empreendedor, as barreiras percebidas ao empreendedorismo, a percepção de risco e a confiança técnica. A metodologia utilizada testa a resposta para cada item ou afirmação e a resposta a questões de caracterização, como o gênero, a idade, o tipo de curso (graduação ou mestrado), o ano do curso, os pais em autoemprego, a opinião sobre empreendedorismo e as atividades empreendedoras. [Nota: a variável idade foi transformada numa nova variável com quatro categorias de acordo com os quartis de idade].

Para conhecer a predisposição empreendedora dos estudantes de engenharia foi apresentada a questão: "Suponha que inesperadamente herda 20 000 euros, como investia esse dinheiro?" (Adaptado de Raijman, 2001). Da amostra, $23,27 \%$ admite que "Investia num negócio próprio". A maioria dos respondentes mostra pouca vontade empreendedora pela escolha das opções: depósito numa conta bancária $(33,76 \%)$, investir num fundo de investimento $(27,37 \%)$, investir num carro ou casa própria $(7,65 \%)$ ou mesmo outro $(6,91 \%)$. Apenas $1,02 \%$ "não sabe ou não responde" à questão.

Foram realizados testes de Qui-Quadrado e encontradas relações de dependência da predisposição empreendedora com o gênero $(X 2(4)=8,659$, p $<0.10$ ), a idade $(X 2(12)=28,682, p<0.01)$, as atitudes sobre empreendedorismo ( $x 2$ $(4)=27,741, p<0.01)$ e as atividades empreendedoras $(x 2(4)=9,496, p<0.10)$.

A Figura 3, ilustra a distribuição dos resultados, considerando as atitudes dos alunos relativas ao empreendedorismo. Os respondentes que não têm opinião sobre o empreendedorismo admitem depositar o dinheiro numa conta bancária (47,69\%). Por sua vez, os que têm opinião sobre o empreendedorismo admitem investir num negócio $(30,23 \%)$ ou investir num fundo de investimento $(28,68 \%)$. 
Figura 3 - Predisposição e atitudes sobre empreendedorismo

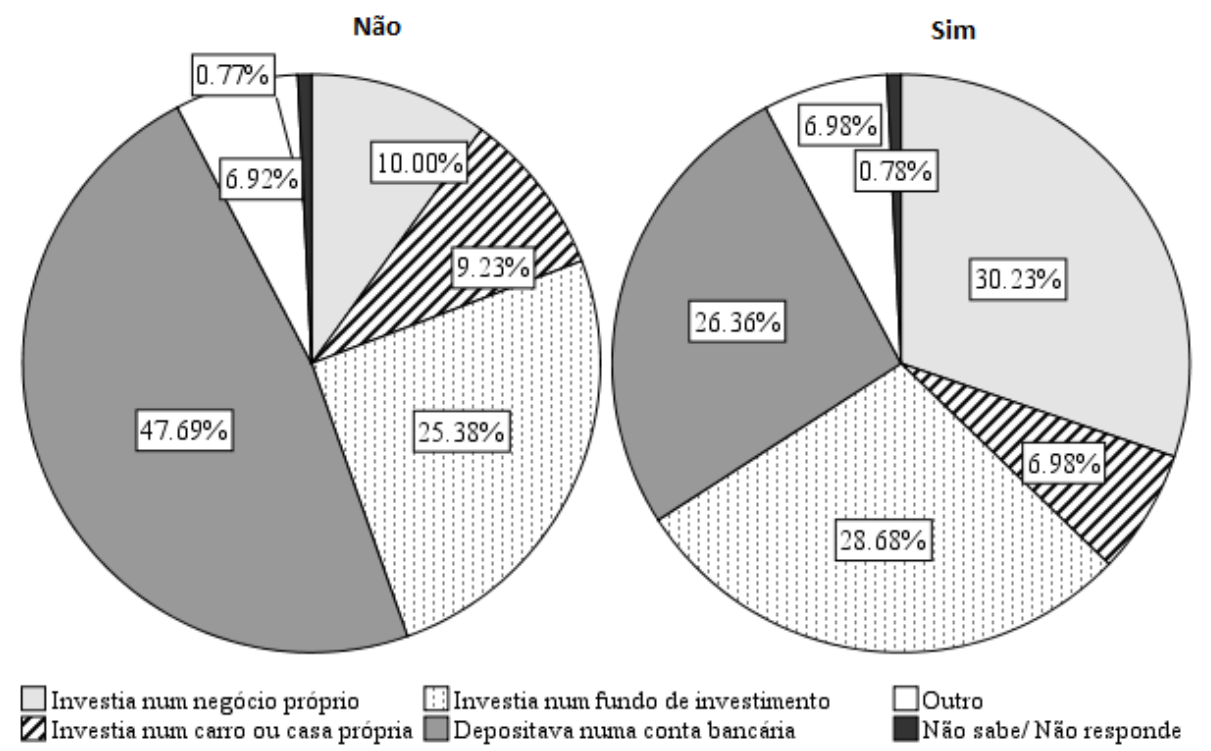

Fonte: Dados da pesquisa (2012)

A atitude face ao autoemprego considera três itens adaptados de Kuckertz e Wagner (2010), (escala de Likert de cinco níveis de concordância). A análise das respostas positivas ("Concordo de alguma forma" ou "Concordo totalmente") mostra percentuais inferiores a $50 \%$, o que sugere baixos níveis de atitude face ao autoemprego (ver Figura 4).

Figura 4 - Atitude face ao autoemprego (\% de respostas positivas)

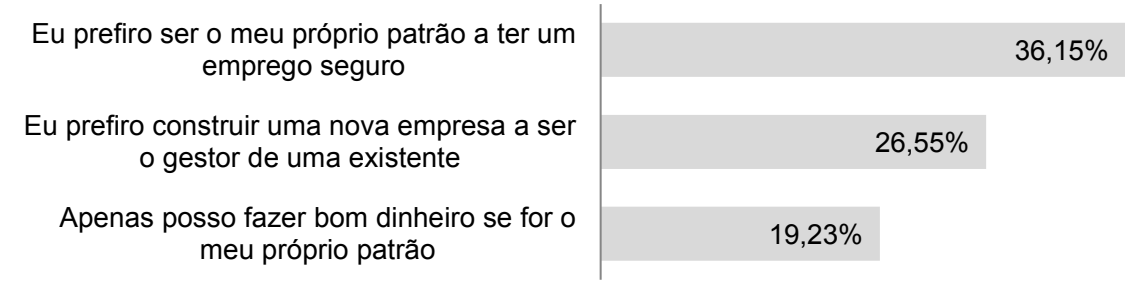

Fonte: Dados da pesquisa (2012)

Relativamente às afirmações sobre a atitude, verificaram-se as seguintes relações de dependência (testes de Qui-Quadrado):

- a afirmação "Eu prefiro constituir uma nova empresa a ser o gestor de uma já existente" revela relações de dependência com o gênero $((x 2(4)=21,560, p$

Revista Produção Online, Florianópolis, SC, v.14, n. 1, p. 242-263, jan./mar. 2014. 
$<0.01)$, o ano do curso $(\mathrm{X} 2(12)=34,537, \mathrm{p}<0.01)$, as atitudes sobre empreendedorismo $(x 2(4)=28,382, p<0.01)$ e o comportamento empreendedor $(X 2(4)=11,291, p<0.05)$;

- por sua vez, "Apenas posso fazer bom dinheiro se for o meu próprio patrão" tem relações de dependência com o gênero $(X 2(4)=8,604, p<0.10)$, o tipo de curso $(X 2(4)=8,362, p<0.10)$ e atitudes sobre empreendedorismo ( $x 2(4)$ $=12,109, \mathrm{p}<0.05)$;

- por fim, "Eu prefiro ser o meu próprio patrão a ter um emprego seguro" mostra relações de dependência com os pais autoempregados $(X 2(4)=9,190, p$ $<0.10)$ e atitudes sobre empreendedorismo $(X 2(4)=25,952, p<0.01)$.

Para medir a imagem que o aluno tem sobre o empreendedor, foram adaptados seis itens de Carayannis et al. (2003) e um item de Kuckertz e Wagner (2010); (escala de Likert de cinco níveis de concordância). As afirmações com maior número de respostas positivas foram "Os empreendedores têm uma imagem positiva na sociedade" (62,92\%) e "Em negócios, é preferível ser um empreendedor do que um empregado numa grande empresa" (40,51\%) (ver Figura 5). Os resultados sugerem que os estudantes reconhecem a imagem positiva do empreendedor na sociedade, mas têm dúvidas sobre o que é melhor (ser empresário ou ser empregado de uma grande empresa). Os resultados para o item "sorte", isto é, "O sucesso de um empreendedor é fortemente determinado pela sorte" (26,36\%) e o item "formação" , i.e., "A formação é mais importante do que a personalidade como fator de sucesso no empreendedorismo" (21,74\%) podem sugerir que os estudantes percebem o esforço do empreendedor (não é "sorte"), mas assumem que a personalidade é um determinante de sucesso mais importante do que a formação (um resultado interessante para os estudantes de engenharia).

As afirmações com menor concordância foram, respetivamente, "O empreendedorismo é basicamente uma saída ou recurso para pessoas que falharam" (4,38\%), "Os empreendedores são convencidos" (9,04\%) e "O empreendedorismo deteriora a vida familiar" $(13,47 \%)$. 
Figura 5 - A imagem percebida do empreendedor

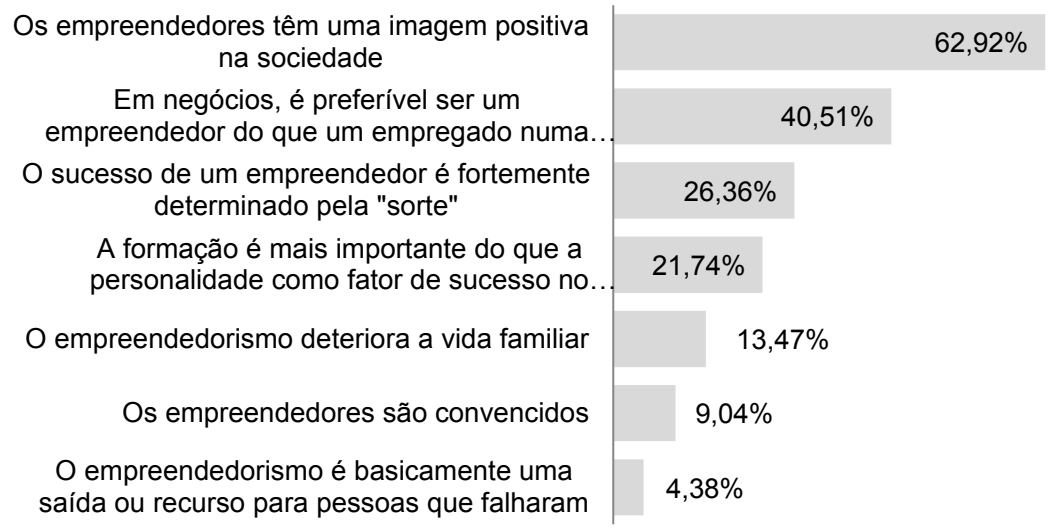

Fonte: Dados da pesquisa (2012)

Com o objetivo de explorar eventuais diferenças nas respostas recebidas nos itens de imagem percebida do empreendedor, decidiu realizar uma análise do perfil médio em função de uma variável de caraterização. As variáveis escolhidas foram: gênero e atitudes sobre empreendedorismo, e a Figura 6 ilustra os perfis médios obtidos. Na análise do gráfico, pode-se concluir que:

- o gênero masculino tende a ter níveis médios de resposta mais elevados comparativamente ao gênero feminino;

- ao considerar as atitudes sobre empreendedorismo, os perfis médios de resposta diferem, ainda que ligeiramente: os alunos com atitudes empreendedoras tendem a concordar mais com as afirmações positivas (por exemplo na afirmação "Em negócios, é preferível ser um empreendedor do que um empregado numa grande empresa") e a discordar mais com afirmações negativas (por exemplo na afirmação "O empreendedorismo é basicamente uma saída ou recurso para pessoas que falharam ").

Revista Produção Online, Florianópolis, SC, v.14, n. 1, p. 242-263, jan./mar. 2014. 
Figura 6 - Perfil médio de acordo com a imagem percebida

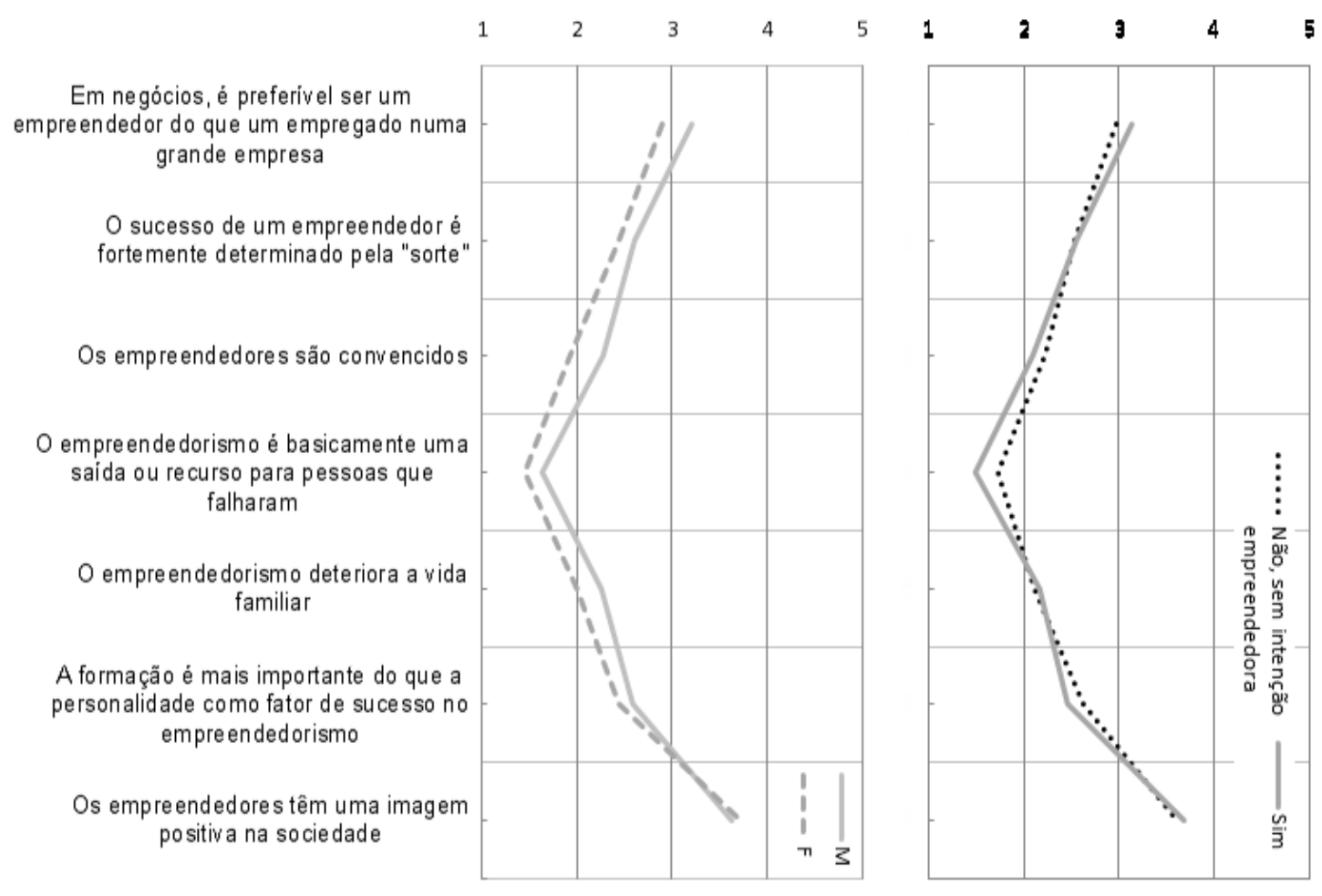

Fonte: Dados da pesquisa (2012)

Para completar a análise da imagem percebida sobre o empreendedor, foram testadas as diferenças entre as médias da variável de caraterização, i.e., a variável gênero e a variável atitudes sobre empreendedorismo (testes $t$, com amostras independentes). Para o gênero foram encontradas diferenças significativas $(p<0.10)$ em todos os itens avaliados, com a exceção de duas afirmações: "A formação é mais importante do que a personalidade como fator de sucesso no empreendedorismo" e "Os empreendedores têm uma imagem positiva na sociedade". Quando se analisou as médias de resposta da variável atitudes sobre empreendedorismo, foi identificada apenas uma diferença significativa na afirmação "O empreendedorismo é basicamente uma saída ou recurso para pessoas que falharam" ( $p<0.05)$.

A análise da percepção das barreiras ao empreendedorismo resultou da utilização e adaptação dos três itens de Kuckertz e Wagner (2010) (escala Likert de 5 níveis de concordância). As respostas positivas obtidas nos três itens estão resumidas na Figura 7. A análise sugere que os estudantes de engenharia compreendem a dificuldade de encontrar uma ideia original ("É difícil encontrar uma Revista Produção Online, Florianópolis, SC, v.14, n. 1, p. 242-263, jan./mar. 2014. 
ideia para um negócio que não tenha sido identificada") com 60,26\% de respostas positivas, bem como a dificuldade de acesso a empréstimos bancários ("Os bancos não dão facilmente crédito para o início das empresas") com 55,27\% de respostas positivas. Dos respondentes, apenas 35,84\% reconhecem a barreira legislativa referente a gestão de uma empresa.

Figura 7 - Percepção das barreiras ao empreendedorismo (\% de respostas positivas)

\begin{tabular}{c|c}
$\begin{array}{c}\text { É difícil encontrar uma ideia para um negócio } \\
\text { que não tenha sido identificada }\end{array}$ & $60,26 \%$ \\
$\begin{array}{c}\text { Os bancos não dão facilmente crédito para o } \\
\text { início das empresas }\end{array}$ & $55,27 \%$ \\
$\begin{array}{c}\text { A legislação é adversa à gestão de uma } \\
\text { empresa }\end{array}$ & $35,84 \%$
\end{tabular}

Fonte: Dados da pesquisa (2012)

$\mathrm{Na}$ tentativa de explorar possíveis relações de dependência (testes de QuiQuadrado) das barreiras percebidas ao empreendedorismo com as variáveis de caracterização foi possível concluir que:

- para a afirmação "É difícil encontrar uma ideia para um negócio que não tenha ainda sido identificada" não foram encontradas relações de dependência;

- a afirmação "Os bancos não dão facilmente crédito para o início de empresas" depende apenas das atividades empreendedoras $(X 2(4)=8,266, p<0.10)$;

- a afirmação "A legislação é adversa à gestão de uma empresa" depende apenas de gênero $(x 2(4)=13,742, p<0.01)$.

A pesquisa avaliava igualmente o conhecimento sobre o risco associado ao empreendedorismo. Nesse sentido, adaptaram-se três itens de Carayannis et al. (2003), numa escala de Likert de 5 níveis de concordância. A Figura 8 resume as respostas positivas obtidas. É interessante notar que uma proporção significativa dos respondentes concordam com as afirmações "Eu gosto de desafios. Muitos dos melhores momentos da minha vida ocorreram quando lutava para atingir um objetivo difícil" (74,94\%) e "Iniciar o meu próprio negócio é arriscado, posso perder tudo". Esta dualidade revela um gosto por desafios que poderá não incluir o início do seu 
próprio negócio, uma vez que é percebido como arriscado! Esta conclusão pode ser reforçada com o resultado obtido na afirmação "É verdade que somos o nosso próprio patrão mas gerir a nossa própria empresa implica muito trabalho e responsabilidade e apenas traz grandes dores de cabeça" com 49,87\% de respostas positivas, o que sugere que os estudantes poderão hesitar porque percebem o trabalho extra e a responsabilidade que implica ser patrão.

Figura 8 - Risco percebido (\% de respostas positivas)

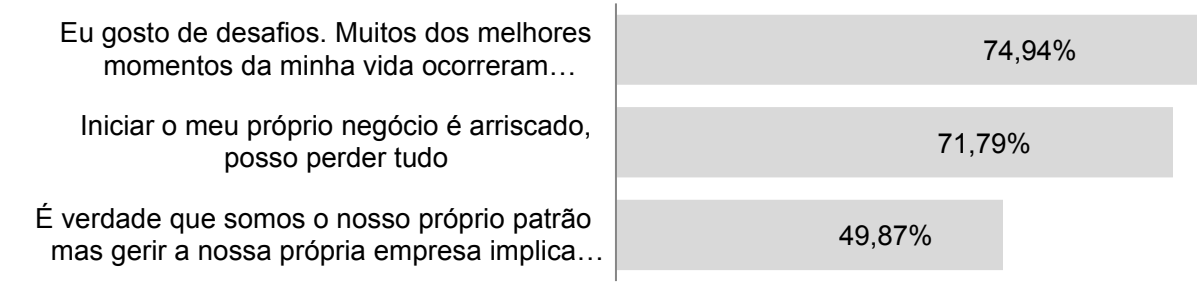

Fonte: Dados da pesquisa (2012)

No que diz respeito as possíveis relações de dependência (testes de QuiQuadrado) das afirmações de risco percebido com as variáveis de caraterização verificou-se que:

- a afirmação "Eu gosto de desafios. Muitos dos melhores momentos da minha vida ocorreram quando lutava para atingir um objetivo difícil" depende do curso $(x 2(12)=20,019, p<0.10)$, das atitudes sobre empreendedorismo $\left(x^{2}\right.$ $(4)=21,007, p<0.01)$ e do comportamento empreendedor $(x 2(4)=11,539, p$ $<0.05)$;

- a afirmação "Iniciar o meu próprio negócio é arriscado, posso perder tudo" só depende do comportamento empreendedor $(X 2(4)=12,714, p<0.05)$;

- não há relação de dependência para a afirmação "É verdade que somos o nosso próprio patrão mas gerir a nossa própria empresa implica muito trabalho e responsabilidade e apenas traz grandes dores de cabeça".

Segundo o trabalho de Oosterbeek et al. (2010), definiu-se um total de 10 afirmações numa escala de Likert de 5 níveis de concordância, para analisar as capacidades e competências. A análise das respostas positivas apresentadas graficamente na Figura 9, sugere uma elevada adaptabilidade ("Eu adapto os meus 
planos às alterações das circunstâncias", com 79,49\%), perseverança ("Eu sou sempre perseverante até atingir os meus objetivos" com $74,81 \%$ ), confiança técnica ("O meu conhecimento técnico é muito bom", com 67,96\%) e orientação para resultados ("Eu sou extremamente orientado para atingir resultados", com 67,10\%). A afirmação com menor concordância foi "Eu prefiro que as outras pessoas decidam por mim" (9,49\%), o que indicia a independência dos inquiridos. Por sua vez, a afirmação sobre os conhecimentos financeiros ("Os serviços financeiros são complicados e confusos para mim") tem apenas $29,38 \%$ de respostas positivas, o que sugere um resultado interessante para uma amostra constituída por estudantes de engenharia. Inesperadamente, a afirmação "Quando eu começo algo de novo, eu sei que serei bem sucedido" registrou apenas $38,72 \%$ de respostas positivas, o que demonstra uma quebra na confiança dos alunos.

Figura 9 - Capacidades e competências percebidas

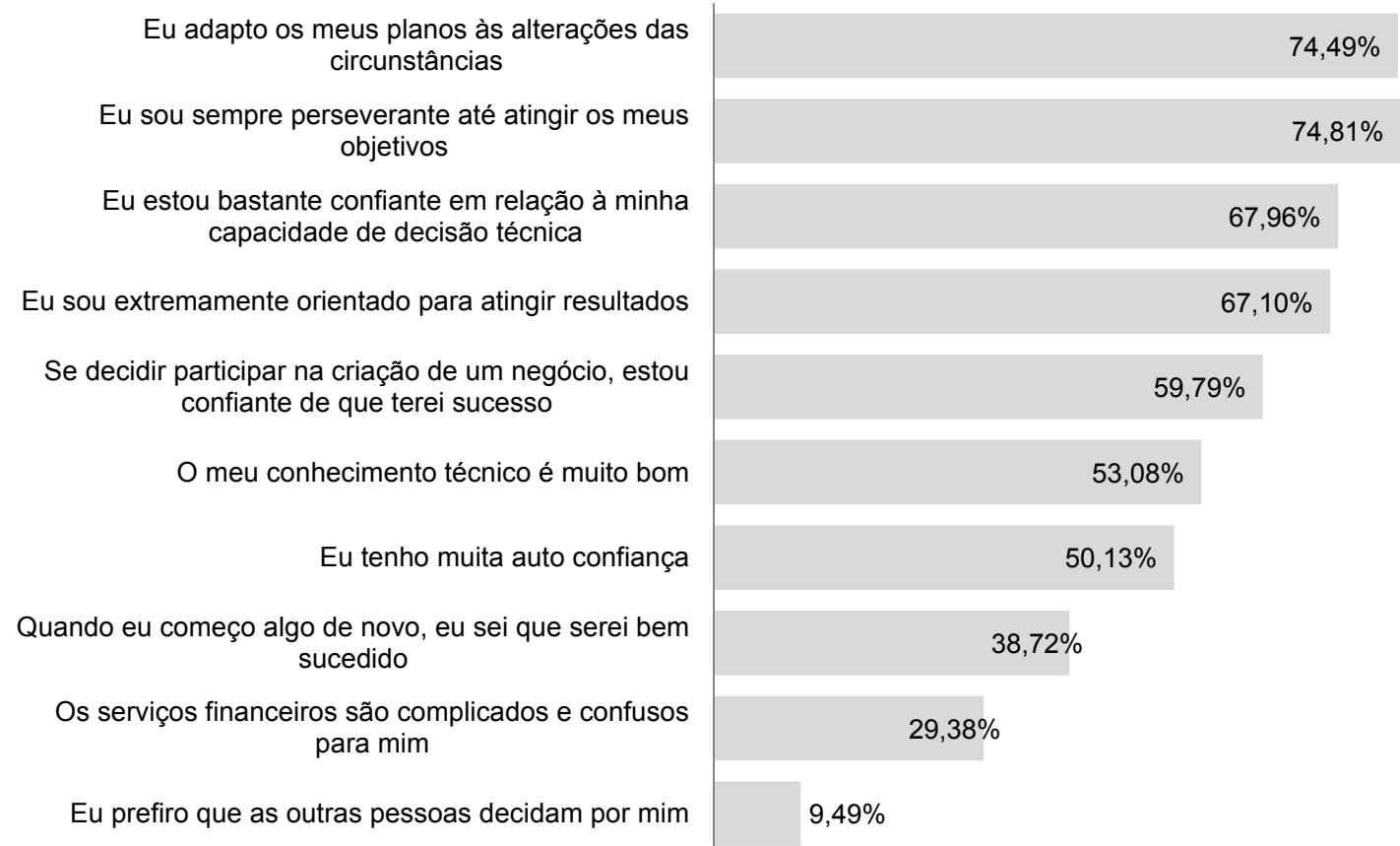

Fonte: Dados da pesquisa (2012)

Face aos resultados obtidos, decidiu-se explorar o perfil médio de respostas de capacidades e competências em função das duas variáveis de caraterização gênero e atitudes sobre empreendedorismo. Os resultados são apresentados na Figura 10. A partir da análise visual do gráfico, pode-se concluir que:

Revista Produção Online, Florianópolis, SC, v.14, n. 1, p. 242-263, jan./mar. 2014. 
- o gênero masculino apresenta uma maior concordância. Foram identificadas diferenças em quatro afirmações: "Eu estou bastante confiante em relação à minha capacidade de decisão técnica", "Eu tenho muita autoconfiança", "Se decidir participar na criação de um negócio, estou confiante de que terei sucesso" e "O meu conhecimento técnico é muito bom";

- os respondentes que têm atitudes sobre empreendedorismo mostram um perfil de maior concordância. Foram identificadas diferenças para as afirmações "Eu tenho muita autoconfiança" e "Se decidir participar na criação de um negócio, estou confiante de que terei sucesso".

Figura 10 - Perfil médio de acordo com as capacidades e competências
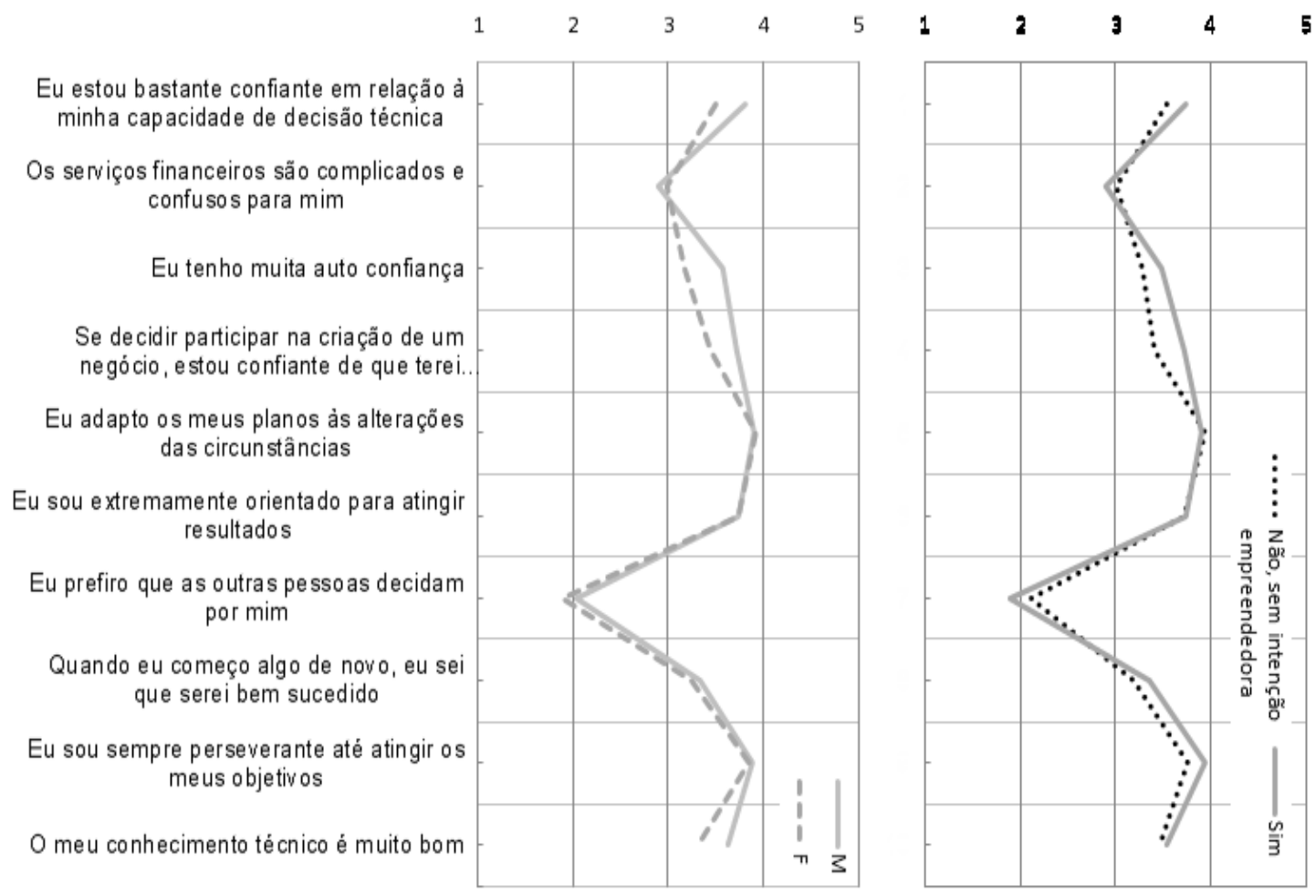

Fonte: Dados da pesquisa (2012)

No seguimento do estudo, também foram aplicados testes às diferenças das médias das respostas dos respondentes segundo o gênero e as atitudes sobre empreendedorismo (testes $t$, com amostras independentes). Para o gênero, foram confirmadas as quatro diferenças identificadas $(p<0.01)$. Uma vez que todas as alegações estão relacionadas com a autoeficácia, é possível concluir que os 
estudantes do gênero feminino tendem a apresentar níveis de confiança mais baixos comparativamente com os estudantes masculinos.

Por sua vez, a variável atitudes sobre empreendedorismo apresenta diferenças significativas (valor de referência de $p<0.10$ ) em seis itens. As exceções foram as quatro afirmações "Os serviços financeiros são complicados e confusos para mim", "Eu adapto os meus planos às alterações das circunstâncias", "Eu prefiro que as outras pessoas decidam por mim" e "O meu conhecimento técnico é muito bom". Os resultados sugerem que os estudantes que pensaram em autoemprego tendem a ser mais confiantes.

\section{CONCLUSÕES}

O empreendedorismo é uma temática que tem recebido um lugar de destaque na agenda política de muitos países. Se por um lado, é reconhecido o seu valor e importância no crescimento econômico, por outro lado, a definição de políticas de incentivo ao empreendedorismo muitas vezes não produzem os efeitos esperados. Portanto, fica a questão: O que é que predispõe alguém a começar seu próprio negócio? A partir da ideia básica de que os cursos de engenharia fornecem a experiência necessária para desenvolver e explorar novas ideias, e uma vez que os novos currículos acadêmicos dos cursos de engenharia incluem disciplinas nas áreas financeiras, este trabalho de investigação tem como principal objetivo compreender e analisar quais os valores, as atitudes $e$ as intenções empreendedoras dos estudantes de engenharia.

Os estudantes de engenharia portugueses apresentam bons níveis de atitudes sobre empreendedorismo. No entanto, quando questionados sobre em que investir o seu dinheiro, uma minoria opta por "Investia num negócio próprio". O estudo realizado permitiu constatar que a predisposição empreendedora tem relações de dependência com o gênero, as atitudes sobre empreendedorismo e o comportamento empreendedor do respondente. $\mathrm{Na}$ investigação, também foi avaliado a atitude dos estudantes de engenharia face ao autoemprego, tendo-se identificado baixos níveis de atitude. Foram igualmente analisadas relações de dependência com as variáveis gênero, atitudes sobre empreendedorismo e a existência de pais em situação de autoemprego ou empreendedores. Por sua vez, Revista Produção Online, Florianópolis, SC, v.14, n. 1, p. 242-263, jan./mar. 2014. 
os resultados sobre a imagem percebida do empreendedor sugerem que os estudantes reconhecem a imagem positiva do empreendedor na sociedade, mas registram dúvidas sobre o que é melhor: ser empreendedor ou empregado de uma grande empresa. Foram igualmente identificadas diferenças nas médias de resposta para as variáveis de caraterização gênero e atitudes sobre empreendedorismo.

Como barreiras ao empreendedorismo, os estudantes de engenharia reconhecem como é difícil encontrar uma ideia de negócio ou acesso a empréstimos bancários. O problema do financiamento está relacionado com a realidade portuguesa, em que o banco continua a ser a principal fonte de financiamento, uma vez que não existem outras organizações (como por exemplo capital de risco, business angels, entre outros) que podem ajudar os indivíduos empreendedores. Ainda assim, os estudantes gostam de desafios, contudo pode não incluir o início do seu próprio negócio (que é compreendido como perigoso!) e apresentam alguma hesitação, relacionada com a percepção de trabalho extra e responsabilidade. As respostas sobre a percepção do risco sugerem a existência de relações de dependência com o comportamento empreendedor do estudante. A percepção das capacidades e competências dos estudantes sugerem uma adaptabilidade elevada, confiança técnica, perseverança e orientação para os resultados. No entanto, e de forma inesperada, revelam uma quebra de confiança relacionada com a ideia de ser bem sucedido como empreendedor. Os resultados também sugerem que os estudantes de engenharia não anteveem a existência de problemas relacionados com os seus conhecimentos financeiros, o que é promissor, uma vez que indica que esta temática não é uma barreira para a criação do próprio emprego.

Os resultados apresentados são preliminares e requerem uma futura análise mais meticulosa, bem como, a necessidade de serem replicados numa amostra maior. Ainda assim, os resultados apresentados são um importante contributo em termos de intenção empreendedora dos estudantes de engenharia.

\section{REFERÊNCIAS}

ANDRADE JÚNIOR, P.P. Análise por agrupamento de fatores de desempenho de empresas de base tecnológica em incubadoras: estudo das incubadoras do Estado de Santa Catarina. Revista Produção Online, v.12, n. 1, p. 205-228, 2012. 
ASKUN, B.; YILDIRIM, N. Insights on entrepreneurship education in public universities in Turkey: creating entrepreneurs or not? Procedia Social and Behavioral Sciences, v. 24, p. 663-676, 2011.

Bennett, R.; Dann, S. The Changing Experience of Australian Female Entrepreneurs, Gender. Work \& Organization, v. 7, n. 2, p. 75-83, 2000.

CARAYANNIS, E. G.; EVANS, D.; HANSON, M. A cross-cultural learning strategy for entrepreneurship education: outline of key concepts and lessons learned from a comparative study of entrepreneurship students in France and the US.

Technovation, v. 23, p. 757-771, 2003.

CURTEIS, H. Entrepreneurship in a growth culture. Long Range Planning, v. 30, n. 2, p. 267-155, 1997.

D' ESTE, P.; MAHDI, S.; NEELY, A.; RENTOCCHINI, F. Inventors and entrepreneurs in academia: What types of skills and experience matter? Technovation, v. 32, p. 293-303, 2012.

DOLABELA, F. Oficina do Empreendedor. Rio de Janeiro: GMT Editores Ltda., 2008.

DRUCKER, P.F. Innovation and Entrepreneurship. Harper Business, 2006.

FRUGIER, D.; VERZAT, C.; BACHELET, R.; ANNACHI, A. Helping engineers to become entrepreneurs. Attitudes, behaviours, beliefs, skills: what are the educational factors in their entrepreneurial spirit? In: IntEnt 2003 INTERNATIONALISING ENTREPRENEURSHIP EDUCATION AND TRAINING, 2003. Anais... Grenoble, France, 2003.

GEM. GEM Portugal 2010 Report. Portugal, 2010.

HARBI, S. E.; ANDERSON, A. R. Institutions and the shaping of different forms of entrepreneurship. The Journal of Socio-Economics, v. 39, n. 3, p. 436-444, 2010.

HEERTJE, A. Schumpeter's Model of the Decay of Capitalism. In: H. Frisch (ed.), Schumpeterian Economics, Prager Publishers, Sussex, UK, Chapter 5, 1982.

HISRICH, R. D.; PETERS, M. P.; SHEPHERD, D. A. Empreendedorismo. Traduzido por Teresa Felix de Sousa, 7. ed., Porto Alegre: Bookman, 2009.

INE - Instituto Nacional de Estatística (Statistics Portugal). Destaque - Estatísticas do Emprego, 4º Trimestre de 2011. Lisboa, Portugal, 2012.

JABBOUR, C.; FONSECA, S.A. A performance de incubadoras empresariais do interior paulista à luz de um novo modelo de avaliação de desempenho. Revista Produção Online, v.5, n. 4, 2005. 
KUCKERTZ, A.; WAGNER, M. The influence of sustainability orientation on entrepreneurial intentions - Investigating the role of business experience. Journal of Business Venturing, v. 25, p. 524-539, 2010.

LASPITA, S.; BREUGST, N.; HEBLICH, S.; PATZELT, H. Intergenerational transmission of entrepreneurial intentions. Journal of Business Venturing, v. 27, n. 4, p. 414-435, 2012.

LEE, L.; WONG, P.K. Attitude towards entrepreneurship education and new venture creation. Journal of Enterprising Culture, v. 11, n. 4, p. 339-357, 2003.

LINI - Lisbon Internet and Networks. Empreendorismo e Inovação nas PME'S em Portugal: a Rede PME Inovação COTEC. Lisboa, Portugal, 2009.

MARTINS, A.A.M.; ANDAJUR, A.M.; GARIBA, C.M.S.; LAPOLLI, E.M.; GAUTHIER, F.A.; MICHELS, G.; GARIBA JÚNIOR, M.; WEIGMANN, P.R.; HAEMING, W.K. Um enfoque empreendedor para a educação a distância: led/ufsc. Revista Produção Online, v. 2, n. 1, 2002.

MIZIARA, G.N.; CARVALHO, M.M. Fatores críticos de sucesso em incubadoras de empresas de software. Revista Produção Online, v.8, n. 3, 2008.

OOSTERBEEK, H.; VAN PRAAG, M.; IJSSELSTEIN, A. The impact of entrepreneurship education on entrepreneurship skills and motivation. European Economic Review, v. 54, p. 442-454, 2010.

RAIJMAN, R. Determinants of entrepreneurial intentions: Mexican immigrants in Chicago. Journal of Socio-Economics, v. 30, p. 393-411, 2011.

SARKAR, S. Empreendedorismo e Inovação. Escolar Editora, 2010.

SINGH, G.; DeNOBLE, A. Views on Self-employment and Personality: An

Exploratory Study. Journal of Developmental Entrepreneurship, v. 8, n. 3, p. 265281, 2003.

SOUITARIS, V.; ZERBINATI, S.; AL-LAHAM, A. Do entrepreneurship programmes raise entrepreneurial intention of science and engineering students? The effect of learning, inspiration and resources. Journal of Business Venturing, v. 22, p. 566591, 2007.

VAN PRAAG, C.M. Some classic views on entrepreneurship. De Economist, v.147, n. 3, p. 311-335, 1999.

VON GRAEVENITZ, G.; HARHOFF, D.; WEBER, R. The effects of entrepreneurship education. Journal of Economic Behavior \& Organization, v. 76, p. 90-112, 2010.

WANG, C.K.; WONG, P. Entrepreneurial interest of university students in Singapore. Technovation, n. 24, p. 163-172, 2004. 
WONG, P. K.; HO, Y. P.; AUTIO, E. Entrepreneurship, Innovation and Economic Growth: Evidence from GEM data". Small Business Economics, v. 24, p. 335-350, 2005.

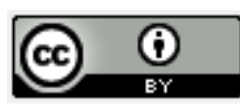

Artigo recebido em 06/05/2013 e aceito para publicação em 16/11/2013.

DOI: http://dx.doi.org/10.14488/1676-1901.v14.i1.1588

Revista Produção Online, Florianópolis, SC, v.14, n. 1, p. 242-263, jan./mar. 2014. 